\title{
Synthesis and Properties of a New AB-Cross-Linked Copolymer Membrane System
}

\author{
J. A. KERRES ${ }^{1, *}$ and H. STRATHMANN ${ }^{2}$
}

'Institut für Chemische Verfahrenstechnik, Universität Stuttgart, Böblinger Str. 72, D-70199 Stuttgart, Germany;

${ }^{2}$ Faculty of Chemical Technology, University of Twente, P.O. Box 217, NL-7500 AE Enschede, The Netherlands

\begin{abstract}
SYNOPSIS
The alcohol permeability and permselectivity properties as well as the morphology of membranes made of a newly developed AB-cross-linked copolymer system composed of elastomeric and glassy components were investigated. The copolymer was synthesized by a hydrosilylation reaction between poly (styrene-stat-isoprenes) $\left(M_{n}\right.$ from 40,000 to 100,000 $\mathrm{g} / \mathrm{mol})$ with high content in unsaturated side groups $(\approx 60 \%$ of entire isoprene content $)$ and polyhydrogen polysiloxanes with varying $\mathrm{SiH}$ content $(0.75-10.7 \mathrm{~mol} \%)$ and molecular mass, $M_{n}$, from 2,500 to $36,000 \mathrm{~g} / \mathrm{mol}$. A two-track approach was taken to determine the morphology of the copolymer system. The first employed the usual polymer characterization methods such as electron microscopy, DSC, IR spectroscopy, the density gradient method, and mechanical measurements. For the second approach, different copolymer permeability models were tested so as to give an insight into the copolymer morphology. As a final step, the permeability and permselectivity properties were correlated with the morphological structure of the copolymer system. It was observed that the respective continuous microphase dominated the copolymer's physical properties, as, e.g., permeability, permselectivity, and mechanical properties. The microphase inversion in the copolymer system was proved by the permeability/permselectivity as well as by the mechanical measurements. (C) 1993 John Wiley \& Sons, Inc.
\end{abstract}

\section{INTRODUCTION}

There is a huge potential for the application of organic solvent-selective dense polymeric membranes in the removal of organic solvents from waste gas, waste water, and bioproduct suspensions. ${ }^{1}$ Therefore, the development of new polymeric membranes with improved fluxes and selectivities has been a focus in applied polymer research and development. ${ }^{2,3}$ In basic polymer research, permeability ${ }^{4,5}$ and permselectivity measurements are useful tools for the investigation of polymer morphology.

This article is focused on the synthesis and characterization of a new copolymer system made from elastomeric siloxane and glassy styrene/isoprene precursor polymers to be used as organic solventselective membranes in membrane separation pro-

* To whom correspondence should be addressed.

Journal of Applied Polymer Science, Vol. 50, 1405-1421 (1993)

(C) 1993 John Wiley \& Sons, Inc. CCC 0021-8995/93/081405-17 cesses, such as pervaporation or vapor separation. Literature data were the basis for selection of copolymers for the present work. ${ }^{6}$

A two-track approach was taken to determine the morphology of the copolymer system. The first employed the usual polymer characterization methods such as electron microscopy, DSC, IR spectroscopy, the density gradient method, and mechanical measurements. For the second approach, different copolymer permeability models were tested to give further insight into the copolymer morphology. Our aim was to obtain a correlation between the results of common polymer characterization methods and the permeation characteristics of the synthesized copolymer system.

To fulfill the applied membrane research aspect of this work, ethanol/water permselectivity measurements of the copolymer system as a function of the elastomeric polymer content of the copolymer system were performed. The results indicate that copolymers with an elastomeric continuous phase 
were ethanol-enriching, whereas copolymers with a continuous glassy phase showed water-selectivity.

\section{BASIC CONSIDERATIONS}

From the solution-diffusion model ${ }^{7}$ of permeation of gases and vapors through polymeric membranes, the permeability $P_{i}$ can be described as the product of the diffusion coefficient $D_{i}$ and the solubility coefficient $S_{i}$ :

$$
P_{i}=D_{i} \times S_{i}
$$

The solubility depends mainly on chemical properties of polymer and permeands. ${ }^{8}$ The diffusivity is determined by the morphology of the polymer and the size of the permeating molecules. ${ }^{8,9}$

Different authors showed, for homologous series of low-molecular organic solvents, that the diffusion coefficient decreases with increasing size/molecular mass of the permeating molecule, whereas the solubility coefficient increases with increasing molecular mass of the permeating species, up to a certain molecular mass: Chen and Edin ${ }^{10}$ performed permeability and diffusivity measurements on glassy polycarbonate membranes with the homologous alkanes $\mathrm{CH}_{4}, \mathrm{C}_{2} \mathrm{H}_{6}, n-\mathrm{C}_{4} \mathrm{H}_{10}, n-\mathrm{C}_{5} \mathrm{H}_{12}$, and $n-\mathrm{C}_{6} \mathrm{H}_{14}$. $\mathrm{He}$ found that permeability and diffusivity decrease with increasing mol mass of the alkane. From the quotient of permeability and diffusivity, they estimated the solubility and found that the solubility increases with the mol mass of the alkane. This can be explained by the increasing condensability of the alkane with increasing mol mass of the alkane--the ease of condensation of a low molecular compound in a polymer is the main factor that determines the solubility coefficient. ${ }^{11}$ Horacek $^{12}$ estimated permeability, diffusivity, and solubility coefficients of $n$-alkanes for membranes of nonglassy LDPE and found that permeability and solubility increase and diffusivity decreases with increasing mol mass of the alkane. Bell ${ }^{8}$ investigated the permeability, diffusivity, and solubility coefficients of a homologous series of alcohols at glassy cellulose and elastomeric polydimethylsiloxane membranes. He found that in the case of cellulose the permeability coefficient and diffusivity decrease, whereas the solubility coefficient increases with increasing mol mass of the alcohol. Polydimethylsiloxane membranes showed increasing permeability and solubility and decreasing diffusivity with mol mass of the alcohol.

The decrease in diffusivity with permeand's molecular mass is much stronger for glassy polymers than for elastomeric polymers. ${ }^{7}$ The diffusion coefficients of low molecular compounds in glassy polymers are 10-1000 times lower than in elastomeric polymers. These experimental results can be explained by chain rigidity in glassy polymers and chain flexibility in elastomeric polymers. ${ }^{7,8}$

For elastomeric polymers, the solubility coefficient dominates the morphology-dependent diffusivity, which leads to increasing permeability with increasing size of the permeand. In contrast to this, glassy polymers show a decreasing permeability with increasing molecular mass of the permeand, because of the dominating influence of the strong decrease in diffusivity with increasing molecular mass of the permeand. As an experimental confirmation of the former assertions, a further publication can be cited: Kajijama et al. ${ }^{13}$ investigated the gas permeability of a blend consisting of $60 \mathrm{wt} \%$ of the liquid-crystalline compound $N$ - (4-ethoxybenzyliden) $-4^{\prime}-n$ butylaniline (EBBA) and of $40 \mathrm{wt} \%$ of bisphenol A-polycarbonate. They found out that this blend can be regarded as morphologically homogeneous. They observed a phase transition from crystalline to nematic liquid-crystalline of the EBBA compound at $304 \mathrm{~K}$. The liquid-crystalline state of the blend is comparable to an elastomeric state because of high mobility of the blend components in the membrane matrix. ${ }^{13}$ The blend showed the following transport characteristics for $\mathrm{CH}_{4}, \mathrm{C}_{3} \mathrm{H}_{8}, i-\mathrm{C}_{4} \mathrm{H}_{10}$, and $n-\mathrm{C}_{4} \mathrm{H}_{10}$ :

- Permeability coefficient: Below $304 \mathrm{~K}$ (in partial crystalline state), the permeability decreases with increasing mol mass of the alkane, whereas between 304 and $311 \mathrm{~K}$, the permeability increases by a factor of 100 and increases with increasing mol mass of the alkane.

- Solubility coefficient: Below and above the liquid-crystalline transition temperature, the solubility coefficients of the alkanes increase with increasing mol mass; the solubility coefficients of the alkanes in the liquid-crystalline state are a factor 5-10 higher than in the partial-crystalline state of the blend.

- Diffusivity: The diffusivities of the alkanes increase by a factor of 100-150 when exceeding the liquid-crystalline transition temperature and decrease with mol mass of the alkane.

From the literature data, it can be concluded that a copolymer membrane with continuous elastomeric component content should selectively separate alcohols from alcohol/water mixtures, whereas a copolymer membrane with continuous glassy compo- 
nent should preferentially remove water from alcohol/water mixtures. It will be investigated whether this conclusion is valid for the elastomeric/ glassy copolymer system synthesized in the work under consideration.

The permeability and permselectivity investigations of this copolymer system should, moreover, give information about the copolymer morphology, supported by other polymer characterization methods.

\section{POLYMER SELECTION AND SYNTHESIS}

As a model system an AB-cross-linked copolymer (nomenclature after a suggestion of Bamford and Eastmond ${ }^{14}$ ) composed of elastomeric oligo/poly$H$-polysiloxanes and glassy styrene/isoprene copolymers was newly developed. ${ }^{9,15}$ This fulfills the selection criteria, such as organic solvent-permselectivity of the elastomeric component, good filmforming properties, mechanical stability of the membranes, easy processability, usability of a wide spectrum of precursor polymers, wide variabilities in polysiloxane content, prepolymer molecular mass, and cross-linking density. The precursor polymers were reacted under a hydrosilylation reaction (Fig. 1 ), yielding $A B$-cross-linked copolymers with a wide property spectrum.

The properties of the copolymer system are the following:
- The chosen copolymer system shows microphase separation, due to the high differences in cohesion energy density between the copolymer components and thus incompatibility.

- Transparent (macroscopic homogen) copolymer films in a polysiloxane content interval from 5 to 91 wt \% siloxane with microphase dimensions of regular block copolymers of 5$300 \mathrm{~nm}$ are obtainable.

- In principle, all polymers with unsaturated side groups-only unsaturated side groups can be hydrosilylated under the applied conditions $\mathbf{s}^{9,16}$ -in a molecular mass interval from 1000 to $1,000,000 \mathrm{~g} / \mathrm{mol}$ can be reacted with polyhydrogen polydimethylsiloxanes having a minimum of $2 \mathrm{SiH}$ groups per molecule and a number of repeating $\mathrm{Si}\left(R R^{\prime}\right)-\mathrm{O}$ units from 2 to $2000 .^{15}$

- The copolymer is a cross-linked copolymer and, therefore, chemically and mechanically stable, due to the $\mathrm{H}$ group content of a minimum of 2 per poly- $H$ polysiloxane molecule.

\section{EXPERIMENTAL}

\section{Styrene/Isoprene Precursor Polymer Synthesis}

The poly (styrene-stat-isoprene) precursor polymers with a high content of isoprene-3,4 units were synthesized via anionic polymerization. The initiator<smiles>[R7]C(=C)C(C)CC([R])CC(C)C([R7])C</smiles>
polymer with unsaturated side groups

(a)<smiles>C[Si]1O[Si](C)(C)C[Si]1(C)O[SiH](C)C</smiles>

polyhydrogen poly(dimethylsiloxane) (general) here: $\alpha, \omega$-dihydrogen poly(dimethylsiloxane)

(b)

hydrosilylation catalyst Hydrosilylation

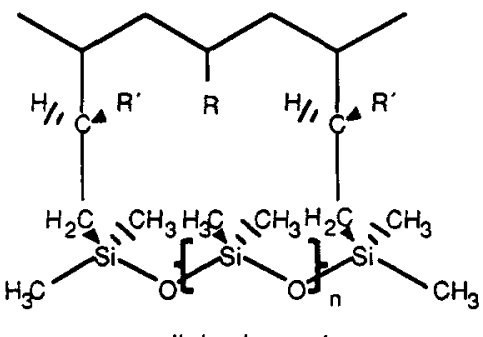

$\mathrm{A}, \mathrm{R}^{\prime}$ : alkyl or anyl group $\mathrm{R}=$ phenyl, $\mathrm{A}^{\circ}=\mathrm{CH}_{3}$ $\downarrow$

statistical styrene/isoprene copolymer with high content in isoprene- 3.4 units

(c)

Figure 1 Scheme for hydrosilylation reaction between a precursor polymer with (a) unsaturated side groups and (b) a polyhydrogen polydimethylsiloxane yielding (c) an ABcross-linked copolymer. 
was $n$-BuLi, solvent cyclohexane/THF mixtures. Addition of THF solvent leads (1) to a strong increase in polymerization rate $^{17}$ and (2) to a high content of isoprene-3.4 units in the poly (styrenestat-isoprenes $)^{18,19}(\approx 60 \%$ isoprene-3.4 units $)$. Instead of THF, other ethers such as ethylene glycol, methyl tert-butyl ether (20), or amines such as tetramethylethylenediamine,${ }^{21}$ may also be used.

The polymerization was performed under Ar with solvents and monomers thoroughly alumina-dried. The solvents and monomers were chromatographed under argon in a chromatography column filled with basic alumina $\mathrm{B}$ super I (supplier ICN). Water, ${ }^{22}$ monomer, and THF stabilizers (4-tert-butyl catechol for styrene and isoprene and butylated hydroxytoluene for THF) and peroxides always present in $\mathrm{THF}^{23}$ are removed effectively by this method.

\section{Example Anionic Polymerization "SI-5"}

- Polymerization: Styrene, $0.6 \mathrm{~mol}$, was added dropwise within $2 \mathrm{~h}$ to a mixture of $0.3 \mathrm{~mol}$ isoprene in $400 \mathrm{~mL}$ cyclohexane $/ 400 \mathrm{~mL}$ THF after initiation with $1.42 \mathrm{~mL}$ BuLi $2.5 \mathrm{M}$ in hexane at $0^{\circ} \mathrm{C}$. The reaction apparatus was held under argon protection gas.

- Resulting polymer: Statistical copolymer, styrene content $72 \mathrm{~mol} \%$, isoprene content $28 \mathrm{~mol}$ $\%$, isoprene-3.4 content $17 \mathrm{~mol} \%$ (determined by $\left.{ }^{1} \mathrm{H}-\mathrm{NMR}\right) ; M_{n}=78,700 \mathrm{~g} / \mathrm{mol}, M_{w} /$ $M_{n}=1.031$ (GPC, styrene calibration); $T_{g}$ $=52^{\circ} \mathrm{C}(\mathrm{DSC})$.

Poly (styrene-stat-isoprenes) with other isoprene concentrations are obtained in the same way by variation of monomer ratios in the reaction mixture. Examples of some poly(styrene-stat-isoprenes) synthesized are listed in Table I.

\section{Synthesis of AB-Cross-Linked Copolymers}

The copolymerization reaction was carried out by dropwise addition of a $20 \mathrm{wt} \%$ solution of polyhydrogen polysiloxane in toluene/xylenes (ACS grade, Aldrich) to $a \approx 10 \mathrm{wt} \%$ solution of a poly (styrenestat-isoprene) in toluene/xylenes ${ }^{9,15}$ under Ar, using a $\mathrm{Pt}$-OL catalyst, supplied by Wacker.

\section{Example}

Copolymerization "AB-17" of 50 wt \% "SI-6" (for composition of SI-6 see Table I) ; and 50 wt \% "HSi2" ( supplier Wacker; for composition of $\mathrm{HSi}-2$, see Table II).

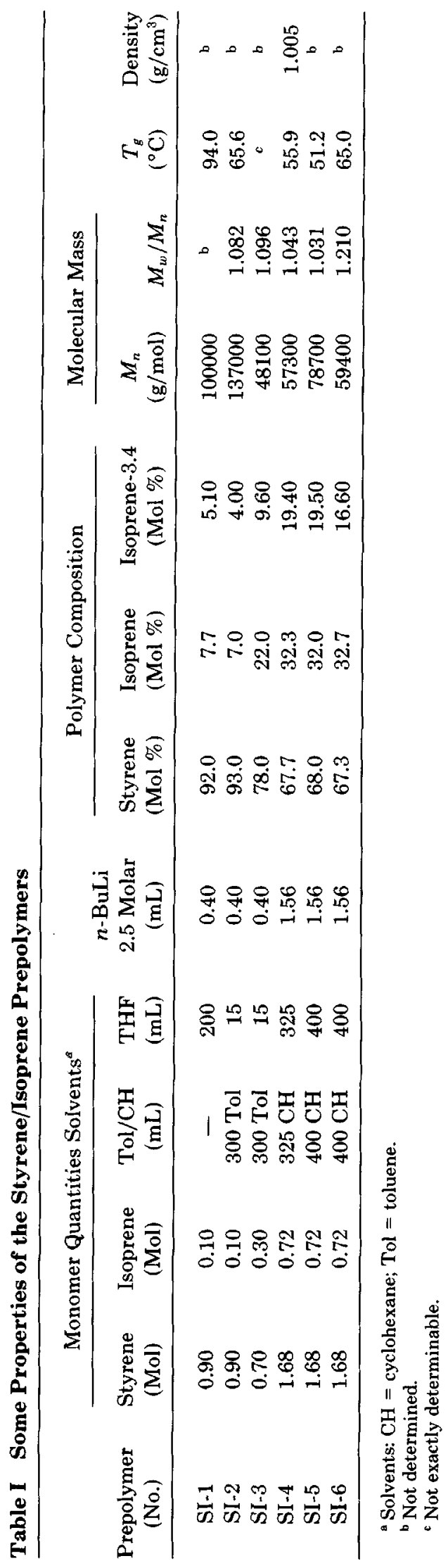


Table II Some Properties of the Poly-H-polysiloxane Prepolymers

\begin{tabular}{|c|c|c|c|c|c|}
\hline \multirow[b]{2}{*}{$\begin{array}{l}\text { Prepolymer } \\
\text { (No.) }\end{array}$} & \multirow[b]{2}{*}{$\begin{array}{c}\mathrm{SiH} \\
(\mathrm{Mol} \%)\end{array}$} & \multicolumn{2}{|c|}{ Molecular Mass } & \multirow[b]{2}{*}{$\begin{array}{c}T_{g} \\
\left({ }^{\circ} \mathrm{C}\right)\end{array}$} & \multirow[b]{2}{*}{$\begin{array}{r}\text { Density } \\
\left(\mathrm{g} / \mathrm{cm}^{3}\right)\end{array}$} \\
\hline & & $\begin{array}{c}M_{n} \\
(\mathrm{~g} / \mathrm{mol})\end{array}$ & $M_{w} / M_{n}$ & & \\
\hline HSi $1^{a}$ & 5.70 & 2480 & 1.671 & b & b \\
\hline $\mathrm{HSi}-2^{\mathrm{a}}$ & 1.74 & 7820 & 1.833 & -122.1 & 0.95 \\
\hline $\mathrm{HSi}-3^{\mathrm{a}}$ & 0.75 & 13900 & 1.990 & -121.0 & b \\
\hline $\mathrm{HSi}-4^{c}$ & 5.60 & 14000 & 1.943 & -122.4 & b \\
\hline
\end{tabular}

${ }^{a} \alpha, \omega$-Di- $H$-polydimethylsiloxane.

${ }^{\mathrm{b}}$ Not determined.

' Oligo- $H$-polydimethylsiloxane.

- Copolymerization: Two grams HSi-2 in 8 g xylene was added dropwise within $20 \mathrm{~min}$ to a $120^{\circ} \mathrm{C}$ hot stirred solution of $2 \mathrm{~g} \mathrm{SI-6}$ in $8 \mathrm{~g}$ xylene that was diluted with further $45 \mathrm{~mL} \mathrm{xy-}$ lene and that contained $0.066 \mathrm{~mL}$ of catalyst OL-cat Wacker). After addition of polysiloxane solution, the temperature was raised to $140^{\circ} \mathrm{C}$ and stirred for a further $80 \mathrm{~min}$. After that time, the solution was directly used for membrane preparation (see below).

- Copolymers: As a result, transparent, mechanically stable films were obtained. The hydrosilylation degree was $100 \%$, referring to
SiH content of the polysiloxane. Further copolymerization examples (together with some properties of the copolymers) are given in Table III.

\section{Membrane Preparation}

The hot copolymer solution, which already had partially reacted, was poured into an alumina bowl that had been oriented horizontally in a vacuum oven. The solvent was evaporated at a temperature of $140^{\circ} \mathrm{C}$ with a membrane pump at 400 mbar. After

Table III Reaction Data of Some Copolymers

\begin{tabular}{|c|c|c|c|c|c|c|c|}
\hline \multirow[b]{2}{*}{$\begin{array}{l}\text { Copolymer } \\
\text { (No.) }\end{array}$} & \multicolumn{2}{|c|}{$\begin{array}{c}\text { Reaction Partners as } 20 \mathrm{Wt} \% \\
\text { Solutions in Xylenes }\end{array}$} & \multirow[b]{2}{*}{$\begin{array}{c}\text { Siloxane Content } \\
\text { in Copolymer } \\
(\mathrm{Wt} \%)\end{array}$} & \multirow[b]{2}{*}{$\begin{array}{l}\text { Additional } \\
\text { Solvent } \\
\text { (mL) }\end{array}$} & \multirow[b]{2}{*}{$\begin{array}{c}\text { OL } \\
\text { Catalyst } \\
\text { (mL) }\end{array}$} & \multirow[b]{2}{*}{$\begin{array}{c}\text { Reaction } \\
\text { Temp } \\
\left({ }^{\circ} \mathrm{C}\right)\end{array}$} & \multirow[b]{2}{*}{$\begin{array}{c}\text { Reaction } \\
\text { Time } \\
\text { (min) }\end{array}$} \\
\hline & $\begin{array}{c}\text { Poly(st-stat-is) } \\
\text { (g) }\end{array}$ & $\begin{array}{l}\text { Oligo- } H- \\
\text { Siloxane (g) }\end{array}$ & & & & & \\
\hline AB-1 & SI-1: 4 & $\mathrm{HSi}-4: 3,8$ & $49 \mathrm{HSi}-4$ & 一 & 0.600 & 25 & 60 \\
\hline AB-3 & SI-2: 1 & HSi-4: 2,07 & $67.4 \mathrm{HSi}-4$ & Toluene 15 & 0.100 & 70 & 60 \\
\hline AB-6 & SI-4: 7,02 & HSi-7: 7.02 & $50 \mathrm{HSi}-2$ & Xylene 50 & 0.350 & $90-100$ & 100 \\
\hline AB-9 & SI-4: 2,76 & HSi-2: 11,06 & $80 \mathrm{HSi}-2$ & Xylene 50 & 0.140 & 80 & 40 \\
\hline AB-7 & SI-4: 4,9 & HSi-2: 9,1 & $65 \mathrm{HSi}-2$ & Xylene 50 & 0.170 & 100 & 80 \\
\hline AB-5 & SI-4: 11,4 & HSi-2: 7,6 & $40 \mathrm{HSi}-2$ & Xylene 50 & 0.380 & 80 & 120 \\
\hline AB-8 & SI-4: 3,9 & HSi-2: 10,08 & $72 \mathrm{HSi}-2$ & Xylene 50 & 0.150 & $80-100$ & 60 \\
\hline AB-10 & SI-5: 7 & HSi $1: 13$ & $65 \mathrm{HSi}-1$ & Xylene 80 & 0.230 & 80 & 30 \\
\hline AB-12 & SI-5: 7 & HSi-2: 13 & $65 \mathrm{HSi}-2$ & Xylene 80 & 0.230 & $80-120$ & 80 \\
\hline AB-13 & SI-6: 1,6 & HSi-2: 2,4 & $60 \mathrm{HSi}-2$ & Xylene 40 & 0.056 & 100 & 80 \\
\hline AB-15 & SI-6: 2,4 & HSi-2: 0,6 & $20 \mathrm{HSi}-2$ & Xylene 50 & 0.150 & $140-150$ & 240 \\
\hline AB-16 & SI-6: 2,8 & HSi-2: 1,2 & $30 \mathrm{HSi}-2$ & Xylene 45 & 0.110 & $120-140$ & 240 \\
\hline AB- 17 & SI-6: 2 & HSi-2: 2 & $50 \mathrm{HSi}-2$ & Xylene 45 & 0.066 & $120-140$ & 100 \\
\hline AB-18 & SI-6: 1,2 & HSi-2: 2,8 & 70 HSi-2 & Xylene 45 & 0.047 & 120 & 60 \\
\hline$A B-19$ & SI-6: 0,8 & HSi-2: 2,1 & 80 HSi-2 & Xylene 45 & 0.040 & $90-100$ & 60 \\
\hline AB-20 & SI-6: 1,95 & HSi-2: 1,05 & $35 \mathrm{HSi}-2$ & Xylene 30 & 0.086 & $140-150$ & 180 \\
\hline$A B-21$ & SI-6: 2,25 & HSi-2: 0,75 & $25 \mathrm{HSi}-2$ & Xylene 30 & 0.120 & $140-150$ & 240 \\
\hline
\end{tabular}




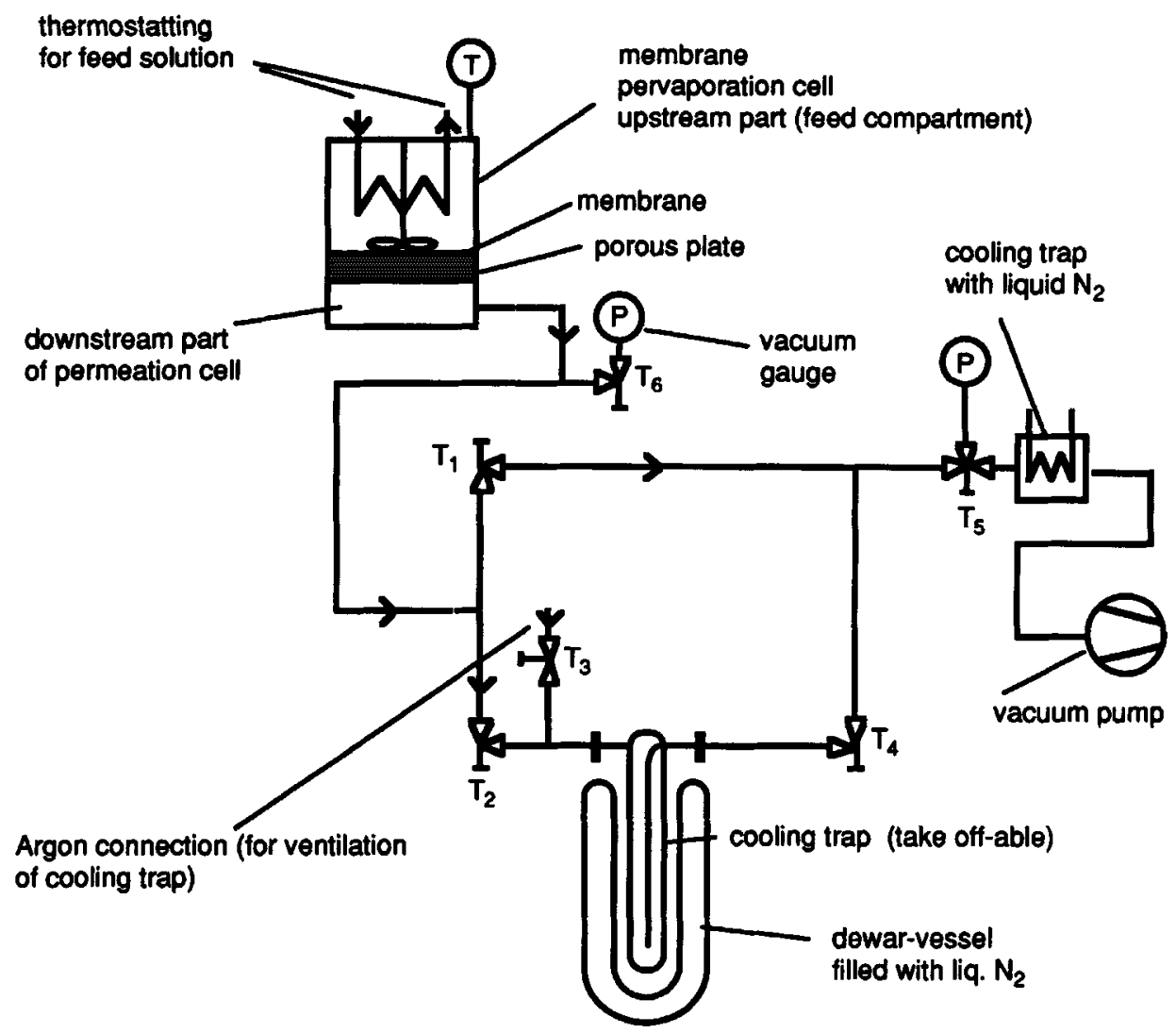

Figure 2 Vacuum pervaporation setup.

evaporation of most of the solvent, the vacuum was raised to 50 mbar to evaporate residual solvent. After that, the membrane was carefully removed off the bowl with a doctor knife and stored for a further 2 days in the vacuum oven at $100^{\circ} \mathrm{C}$ and 50 mbar.

\section{Pervaporation Measurements (Permeability/ Permselectivity)}

Pervaporation of pure alcohols and of ethanol/water mixtures was performed by the ordinary pervaporation technique (see, e.g., Ref. 24). The setup used for pervaporation measurements to estimate permeability coefficients is shown in Figure 2.

A thermostated, stirred pervaporation cell made by Berghof was used. The pervaporation variant used was vacuum pervaporation. The membrane (diameter $76 \mathrm{~mm}$ ) was placed in the cell, and the cell was sealed and filled with the feed liquid in the upper cell part. The downstream part of the cell was connected to the pervaporation apparatus, valves $T_{1}$ and $T_{5}$ were opened (with valves $T_{2}$ and $T_{4}$ closed), and the upper part of the apparatus was evacuated to oil pump vacuum (0.1-0.5 mbar). Now,
$T_{1}$ was closed, while $T_{4}$ was opened. The lower part of the vacuum apparatus was now evacuated. After reaching a vacuum of $0.1-0.5$ mbar, $T_{4}$ again was closed and the cooling trap was dipped into the liquid $\mathrm{N}_{2}$-filled cooling trap. After waiting 2-3 min, $\mathrm{T}_{1}$ was opened for $5 \mathrm{~min}$ until, again, a vacuum of $0.1-0.5$ mbar was reached. $T_{1}$ was then closed, $T_{2}$ and $T_{4}$ were opened, and the stop clock was started. Now the permeate was frozen out in the cooling trap. After the desired permeating time had elapsed, $T_{2}$ and $T_{4}$ were closed and $T_{1}$ was opened. The dewar vessel was removed, and $T_{3}$ was opened to ventilate the lower part of the pervaporation apparatus with argon; the permeate was allowed to thaw. After thawing, the cooling trap with the permeate was removed and weighed. The cooling trap was dried and again weighed. In this way, the mass of permeand permeated in the desired time was determined.

The permeability coefficient of the permeated component $i$ is calculated via eq. (2):

$$
P_{i}=\frac{m_{\text {Permeate }}}{A_{\text {Membrane }} \times \Delta t} \times \frac{\Delta z}{\Delta p_{i} \times M_{\text {molar }}}\left(\frac{\text { mol }}{\text { mhbar }}\right)
$$


with $P_{i}$ the permeability of solvent $i(\mathrm{~mol} / \mathrm{mhbar})$; $m_{\text {Permeate }}$ the mass of permeate in cooling trap $(\mathrm{g})$; $\Delta z$ the membrane thickness $(\mathrm{m}) ; \Delta p_{i}$ the partial pressure difference between feed and permeate (bar) [ approximately $\Delta p_{i}=p_{i s}-p(\mathrm{vac}) \approx p_{i s}$ with $p$ (vac) $\approx 0$ with $p_{i s}=$ saturation pressure of permeating component $i$ at the reference temperature ]; and $M_{\text {molar }}$ the molar mass of the solvent $(\mathrm{g} / \mathrm{mol})$.

Equation (2) is based on the permeation equation

$$
J_{i}=-P_{i} \frac{p_{i s}}{\Delta z}
$$

with $J_{i}$ the flow of component $i$ through the membrane in $\left(\mathrm{mol} / \mathrm{m}^{2} \mathrm{~h}\right)$ and the equation

$$
J_{i}=\frac{m_{\text {Permeate }}}{A_{\text {Membrane }} \times \Delta t}\left(\frac{\mathrm{mol}}{\mathrm{m}^{2} \mathrm{~h}}\right)
$$

For the pervaporation of mixtures, a standardized flow $J_{\text {norm }}$ was calculated via

$$
\begin{gathered}
J_{\text {norm }}=J \times \Delta z\left(\frac{\mathrm{g}}{\mathrm{mh}}\right) \\
J \text { overall flow of the mixture }\left(\frac{\mathrm{g}}{\mathrm{m}^{2} \mathrm{~h}}\right)
\end{gathered}
$$

The separation factor $\alpha_{\mathrm{H}_{2} \mathrm{O}}^{\mathrm{EtOH}}$ of the pervaporation of ethanol/water mixtures was calculated using eq. (6). The mass fractions $\gamma_{i}$ of ethanol and water in permeate and feed were ascertained by gas chromatography:

$$
\alpha_{\mathrm{H}_{2} \mathrm{O}}^{\text {EtOH }}=\frac{\gamma_{\mathrm{E}}^{\text {Permeate }}}{\gamma_{\mathrm{EtOH}}^{\text {Feed }}} \times \frac{\gamma_{\mathrm{H}_{2} \mathrm{O}}^{\text {Feed }}}{\gamma_{\mathrm{H}_{2} \mathrm{O}}^{\text {Permeate }}}
$$

The experimentally determined accuracy of permeation and permselectivity measurements was $\pm 7 \%$.

\section{Molecular Mass Determination of Prepolymers}

The molecular mass of poly (styrene-stat-isoprenes) was ascertained by GPC in THF solvent, calibrated by polystyrenes. The molecular mass of polyhydrogen polysiloxanes was determined by GPC in toluene solvent, calibrated by polystyrenes.

\section{Composition of Prepolymers}

The composition of prepolymers ( styrene, isoprene, and isoprene-3,4 content; $\mathrm{SiH}$ content) was deter- mined via analysis of 250,300 , or $360 \mathrm{MHz}^{1} \mathrm{H}$-NMR spectrogram integrals. The method is described in Ref. 25.

\section{Glass Transition Points of Prepolymers and AB-Cross-linked Copolymers}

Glass transition temperatures of prepolymers and copolymers were determined via DSC at WackerChemie, Burghausen. The heating rate was $10^{\circ} \mathrm{C}$; the samples were not tempered before analysis.

\section{Determination of Hydrosilylation Degree of Cross-linked Copolymers}

Hydrosilylation degree analysis of the AB-crosslinked copolymers was performed via FTIR (PerkinElmer 1800, Data Station 7500) by a method described in Ref. 9. The quotient of areas under the $\mathrm{SiH}$ band (2240-2100 $\left.\mathrm{cm}^{-1}\right)$ and a specific $\mathrm{Si}\left(\mathrm{CH}_{3}\right)_{2}$ band (1430-1390 $\left.\mathrm{cm}^{-1}\right)$ of different polyhydrogen polysiloxanes were related to their $\mathrm{SiH}$ content in a diagram. Then, in IR spectrograms of the copolymers, the quotient of $\mathrm{SiH}$ and $\mathrm{Si}\left(\mathrm{CH}_{3}\right)_{2}$ band area was calculated. After that, in the $\mathrm{SiH}$ content/ [ area $\mathrm{SiH} /$ area $\mathrm{Si}\left(\mathrm{CH}_{3}\right)_{2}$ ] diagram, the $\mathrm{SiH}$ content belonging to the respective copolymer band area quotient was read. From this, \% hydrosilylation degree was calculated. The accuracy of this method is $\pm 5 \%$ hydrosilylation degree.

\section{Mechanical Properties of the Copolymers}

The burst strength and elongation-at-break were determined by DIN 53504 N. St. S3A norm.

\section{Micromorphology}

The micromorphology of the copolymer films was determined by transmission electron microscopy (TEM) at Wacker-Chemie. Preparation was made via cryo-cutting or epoxy resin embedding. Micromorphology of the copolymers was made visible by different electron-beam permeabilities of the copolymer microphases.

\section{Polymer Density Determination}

The polymer density was determined via the density gradient tube method at a temperature of $298 \mathrm{~K}$. 
Table IV Some Properties of the Copolymers

\begin{tabular}{|c|c|c|c|c|c|c|c|c|}
\hline \multirow[b]{2}{*}{$\begin{array}{l}\text { AB-cross-linked } \\
\text { Copolymer } \\
\text { (No.) }\end{array}$} & \multicolumn{2}{|l|}{ Composition } & \multirow[b]{2}{*}{$\begin{array}{l}\text { Hydrosilylation } \\
\text { Degree (\%) }\end{array}$} & \multicolumn{2}{|c|}{$\begin{array}{c}T_{g} \text { 's of } \\
\text { Copolymer }\end{array}$} & \multirow[b]{2}{*}{$\begin{array}{l}\text { Density } \\
\left(\mathrm{g} / \mathrm{cm}^{3}\right)\end{array}$} & \multicolumn{2}{|c|}{ Mechanical Data } \\
\hline & $\begin{array}{c}\text { Oligo-H-Polysiloxane } \\
\text { (Wt \%) }\end{array}$ & $\begin{array}{c}\text { St-stat-is } \\
\text { (Wt \%) }\end{array}$ & & $\begin{array}{c}T_{z}^{\text {upper }} \\
\left({ }^{\circ} \mathrm{C}\right)\end{array}$ & $\begin{array}{l}T_{g}^{\text {lower }} \\
\left({ }^{\circ} \mathrm{C}\right)\end{array}$ & & $\begin{array}{l}\text { Burst Strength } \\
\qquad\left(\mathrm{N} / \mathrm{mm}^{2}\right)\end{array}$ & $\begin{array}{c}\text { Elongation- } \\
\text { at-break } \\
(\%)\end{array}$ \\
\hline AB-1 & $49 \mathrm{HSi}-4$ & 51 SI-1 & $<10^{\mathrm{n}}$ & 102.20 & b & c & c & c \\
\hline AB-2 & $65.5 \mathrm{HSi}-4$ & $34.5 \mathrm{SI}-3$ & 100 & 52.80 & -119.3 & c & c & c \\
\hline AB-3 & 67.4 HSi-4 & $32.6 \mathrm{SI}-2$ & 100 & 100.20 & -116.5 & 1.03700 & c & c \\
\hline AB-4 & $30 \mathrm{HSi}-2$ & $70 \mathrm{SI}-4$ & 94 & 53.05 & b & 1.00600 & 10.60 & 37 \\
\hline AB-5 & $40 \mathrm{HSi}-2$ & $60 \mathrm{SI}-4$ & 100 & 54.00 & b & 1.00250 & 15.30 & 39 \\
\hline $\mathrm{AB}-6$ & $50 \mathrm{HSi}-2$ & $50 \mathrm{SI}-4$ & 95 & 53.00 & -117.0 & 1.00050 & 9.30 & 267 \\
\hline $\mathrm{AB}-7$ & $65 \mathrm{HSi}-2$ & $35 \mathrm{SI}-4$ & 94 & $\mathrm{~b}$ & -120.0 & 0.99000 & 4.40 & 300 \\
\hline AB-8 & $72 \mathrm{HSi}-2$ & $28 \mathrm{SI}-4$ & 89 & 52.40 & -118.6 & 0.98550 & 3.00 & 246 \\
\hline AB-9 & $80 \mathrm{HSi}-2$ & $20 \mathrm{SI}-4$ & 89 & $\mathbf{b}$ & -115.0 & 0.98200 & 1.70 & 200 \\
\hline AB-10 & $65 \mathrm{HSi}_{-1}$ & $35 \mathrm{SI}-5$ & 100 & 51.30 & -118.0 & c & $4.50^{c}$ & $136^{c}$ \\
\hline AB-11 & $65 \mathrm{HSi}-3$ & 35 SI-5 & $\mathbf{A}, \mathbf{c}$ & 77.00 & -115.6 & c & $c$ & c \\
\hline AB-12 & $65 \mathrm{HSi}-2$ & $35 \mathrm{SI}-5$ & 100 & b & b & c & 5.09 & 242 \\
\hline AB-15 & $20 \mathrm{HSi}-2$ & $80 \mathrm{SI}-6$ & 100 & 75.90 & -120.0 & $c$ & c & c \\
\hline AB-16 & $30 \mathrm{HSi}-2$ & 70 SI-6 & 100 & 74.80 & -118.4 & c & c & c \\
\hline AB-14 & $40 \mathrm{HSi}-2$ & $60 \mathrm{SI}-6$ & 100 & 74.40 & b & c & c & c \\
\hline AB-17 & $50 \mathrm{HSi}-2$ & $50 \mathrm{SI}-6$ & 100 & 78.50 & -118.4 & c & c & c \\
\hline AB-13 & $60 \mathrm{HSi}-2$ & 40 SI-6 & 100 & b & -114.7 & c & c & c \\
\hline AB-19 & $80 \mathrm{HSi}-2$ & 20 SI-6 & 100 & b & -112.3 & c & c & c \\
\hline
\end{tabular}

- Inhomogeneous copolymer.

b Not exactly determinable.

c Not determined or indeterminable.

\section{RESULTS AND DISCUSSION}

\section{Common Characterization Results}

In Table I, some properties of the styrene/isoprene prepolymers denoted "SI- . . ." are shown; in Table II, some properties of the poly- $H$-polysiloxane prepolymers denoted "HSi - . . ." are shown; whereas in Table IV, characterization results of the common copolymer characterization are listed.

\section{Comments on the Common Characterization Results}

\section{Hydrosilylation Degree}

Figure 3 shows IR spectrograms of prepolymers (a) St-stat-is SI-6, (b) $\alpha, \omega$-di- $H$-PDMS HSi-2, and (c) copolymer AB-19 (80\% HSi-2, 20\% SI-6). Note that the $\mathrm{SiH}$ band (2125-2250 $\mathrm{cm}^{-1}$, arrow) had completely disappeared at the IR spectrogram of AB19. That means that the hydrosilylation degree of the copolymer $\mathrm{AB}-19$ was $100 \%$, compared to $\mathrm{SiH}$ content of the prepolymer HSi-2.

\section{Glass Transition Temperatures of Prepolymers and Copolymers}

DSC investigations of the AB-cross-linked copolymers show clearly the glass transition temperatures of the two polymers making up the copolymer. This means that the copolymer has a microphase-separated morphology. For example, the DSCalorigrams of the polysiloxane prepolymer HSi-2 [Fig. 4(a)], the poly(styrene-stat-isoprene) prepolymer SI-6 [Fig. 4(b)], and the copolymer AB-17 made from $50 \mathrm{wt} \%$ SI-6 and $50 \mathrm{wt} \%$ HSi-2 [Fig. 4(c)] are shown.

The 5-15 degree increase of $T_{g}$ 's of the copolymer microphases, compared with $T_{g}$ 's of the prepolymers, is due to the hindering of the polymer chain segment movements by the cross-linkings between the copolymer components.

\section{Copolymer Density}

The density of a cross-linked copolymer system made from the polysiloxane $\mathrm{HSi}-2$ and the poly (styrene-stat-isoprene) SI-4 as a function of 


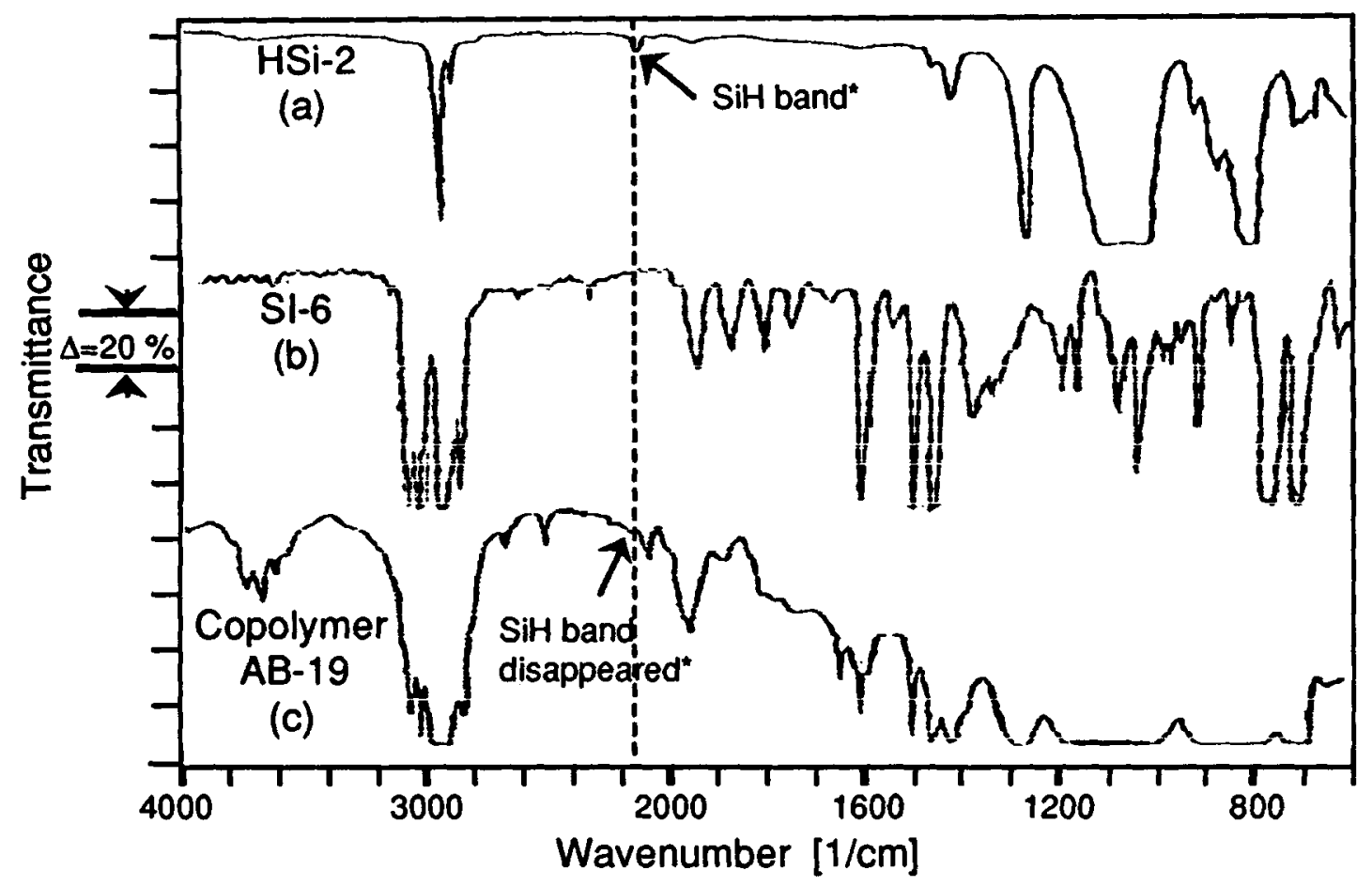

Figure 3 IR spectrograms of prepolymers SI-6 and HSi-2 and cross-linked copolymer AB-19. ${ }^{*}$ Note: The HSi-2 IR spectrum was recorded with a capillary film of HSi-2, whereas the IR spectra of prepolymer SI-6 and copolymer AB-19 were recorded with $\approx 100 \mu \mathrm{m}$ thick films.

polysiloxane content is shown in Figure 5. Equation (7), valid for incompatible copolymer systems ${ }^{26}$ (volume-additivity of the copolymer components, discrete styrene-stat-isoprene polymer and polysiloxane microphases) fits the experimentally determined copolymer densities well:

$$
\frac{1}{\rho}=\frac{\gamma_{\mathrm{HSi}}}{\rho_{\mathrm{HSi}}}+\frac{\gamma_{\mathrm{SI}}}{\rho_{\mathrm{SI}}}
$$

( $\rho:$ density in $\mathrm{g} / \mathrm{cm}^{3} ; \gamma:$ mass fractions of the copolymer components ).

The densities of "pure" copolymer components $\left(\rho_{\mathrm{HSi}-2}, \rho_{\mathrm{SI}-4}\right)$ in eq. $(7)$ were taken from the diagram in Figure 5: The points of intersection of the best linear fitting curve for the experimental densities of the copolymer system with the density axis give the mean density of the copolymer's microphases, estimated to $\rho_{\mathrm{HSi}-2}=0.985\left(\mathrm{~g} / \mathrm{cm}^{3}\right)$ (polysiloxane microphase, $\left.\varphi_{\mathrm{HSi}-2}=1\right)$ and $\rho_{\mathrm{SI}-4}=1.017\left(\mathrm{~g} / \mathrm{cm}^{3}\right)$ [poly (styrene-stat-isoprene) microphase, $\varphi_{\mathrm{HSi}-2}$
$=0]$. When the $\rho_{\mathrm{HSi}-2}$ and the $\rho_{\mathrm{SI}-4}$ values are inserted into eq. (7), a curve results that is identical with the best linear fitting curve for the copolymer's experimental densities. The increased density of the copolymer's microphases, compared to the densities of the prepolymers (see Fig. 5), is due to volume contraction in the copolymer by the cross-linking reaction.

\section{Mechanical Properties of the Copolymers}

In Figure 6, the dependence of burst strength and elongation-at-break on polysiloxane content of a copolymer system made from SI-4 and $\mathrm{HSi}-2$ is shown. It can be seen that in the 40-50 wt \% HSi2 content region, the elongation-at-break value of the copolymer strongly increases, while the burst strength decreases from $40 \mathrm{wt} \% \mathrm{HSi}-2$ content on. This can be interpreted in the following way: In the 0-40 wt \% HSi-2 content region, the rigid, glassy SI-4 poly (styrene-stat-isoprene) builds up the con- 
(a)

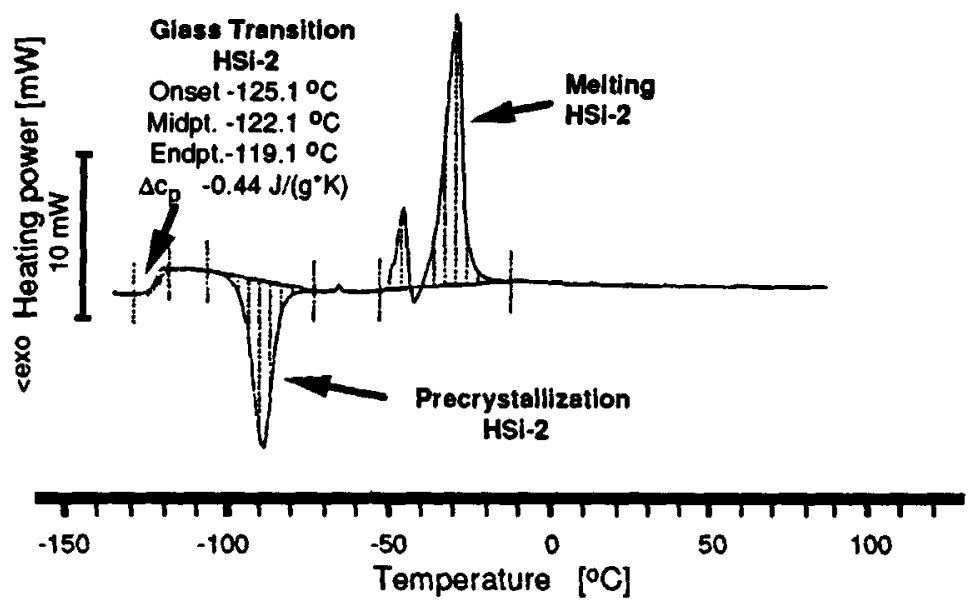

(b)
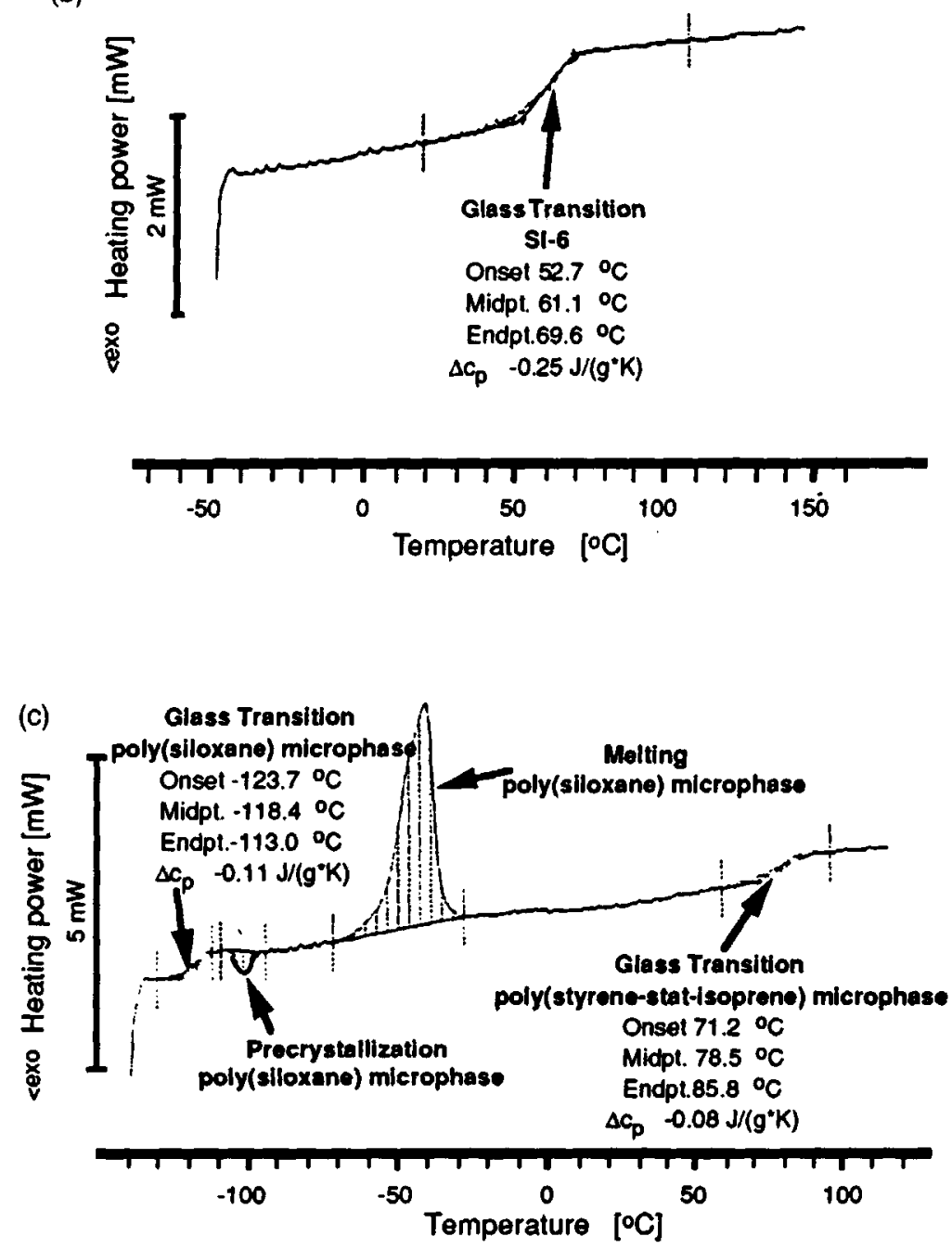

Figure 4 (a) DSCalorigram of the polysiloxane prepolymer HSi-2. (b) DSCalorigram of the poly (styrene-stat-isoprene) prepolymer SI-6. (c) DSCalorigram of the copolymer No. AB-17. 


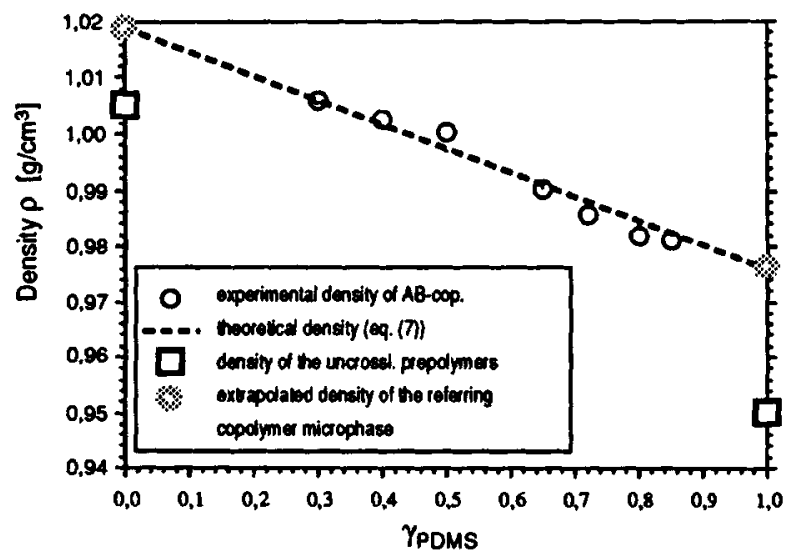

Figure 5 Density of the copolymer system made from SI-4/HSi-2. Intersections of interpolated experimental density curve with density axis of diagram yield mean densities of the SI-4/HSi-2 copolymer microphases. When mean densities of the copolymer's microphases are inserted into eq. (7), a linear curve results that is identical with interpolated experimental density curve.

tinuous copolymer microphase, with the elastomeric HSi-2 microphase dispersed in it. In the 40--50 wt $\% \mathrm{HSi}-2$ content region, a phase inversion of the microphases takes place, and, finally, from 50 to 100 wt \% HSi-2 content, the elastomeric polysiloxane forms the continuous copolymer microphase, with dispersed glassy SI-4 microphase particles. The burst strength reduction from $50 \mathrm{wt} \% \mathrm{HSi}-2$ content on can be explained by decreasing cross-linking density between the copolymer components and, therefore, reduced mechanical stability.

\section{Electron Microscopical Characterization of the Copolymers}

TEM investigations of the copolymers give information about size and shape of microphase particles, because the copolymer microphases consisting of poly (styrene-stat-isoprene) and polysiloxane, respectively, have different electron-beam permeabilities. In Figure 7, electron micrographs of copolymers made from different poly (styrene-stat-isoprenes) and polysiloxanes with different hydrosilylation degrees are shown (for properties of the copolymers, see Table IV). It can be seen from Figure 7 (a) - (d) (for further TEM micrograph examples, see Ref. 9) that the size of copolymer microphases is determined as follows: The higher the chain lengths of prepolymers and/or the lower the content in cross-linkable groups and/or the lower the hydrosilylation degree of the copolymer, the larger the microphase size. The hydrosilylation degree is adjusted by temperature (higher temperature leads to higher hydrosilylation degree) and by amount and sort of hydrosilylation catalyst. ${ }^{15}$

\section{Summary of the Common Copolymer Characterization}

AB-cross-linked copolymer systems made from poly (styrene-stat-isoprenes) with high content in unsaturated isoprene-3,4 side groups and from oligo$H$-polysiloxanes by hydrosilylation show a microphase-separated morphology. This is demonstrated by

- DSC measurements: Copolymers show two glass transition temperatures close to the $T_{g}$ 's of the prepolymers.

- Density dependence: The copolymer density dependence from siloxane content shows a form that can be related to microphase separation of copolymer components. ${ }^{26}$

- Mechanical properties of the copolymer systems: The elongation-at-break rises strongly and the burst strength is clearly reduced from a certain polysiloxane content in the copolymer on, which is a sign for forming of a continuous polysiloxane copolymer microphase.

- TEM micrographs: The copolymers show a structuring that can also be interpreted as microphase separation. The size of microphases is controlled using different prepolymers and/ or variation of copolymerization reaction conditions.

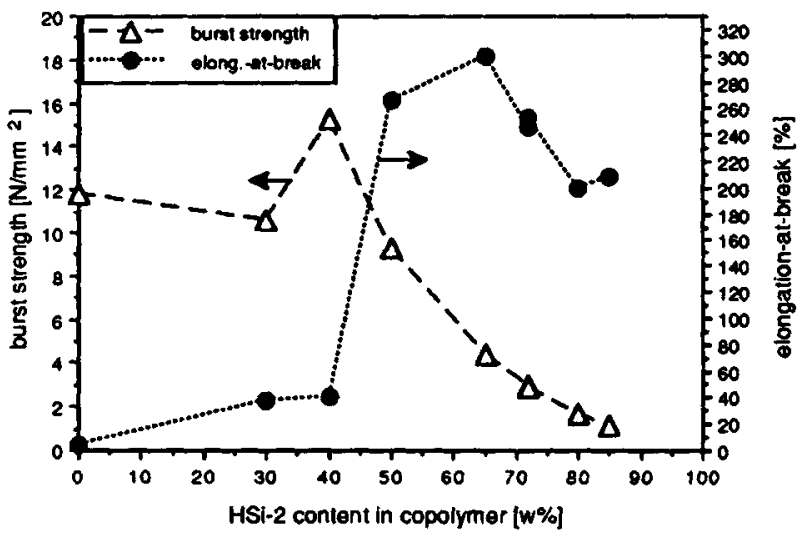

Figure 6 Dependence of burst strength and elongationat-break from the HSi-2 content of a copolymer system made from SI-4 and HSi-2. 


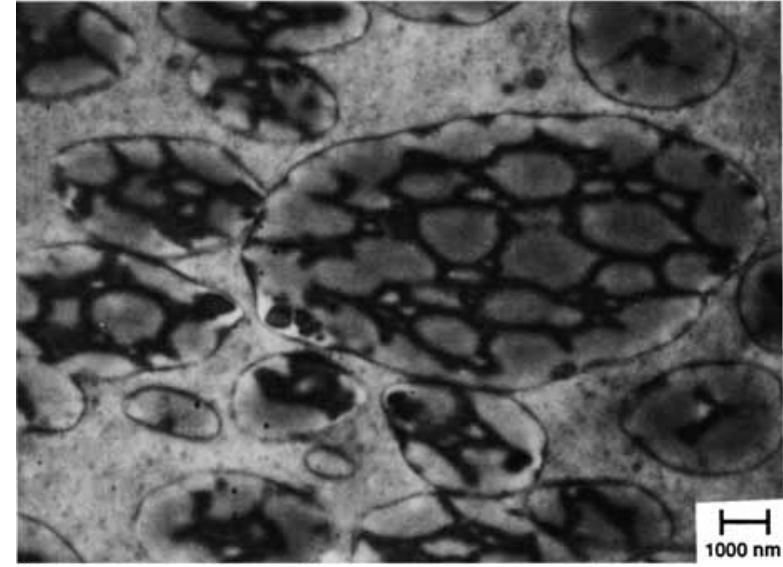

(a)

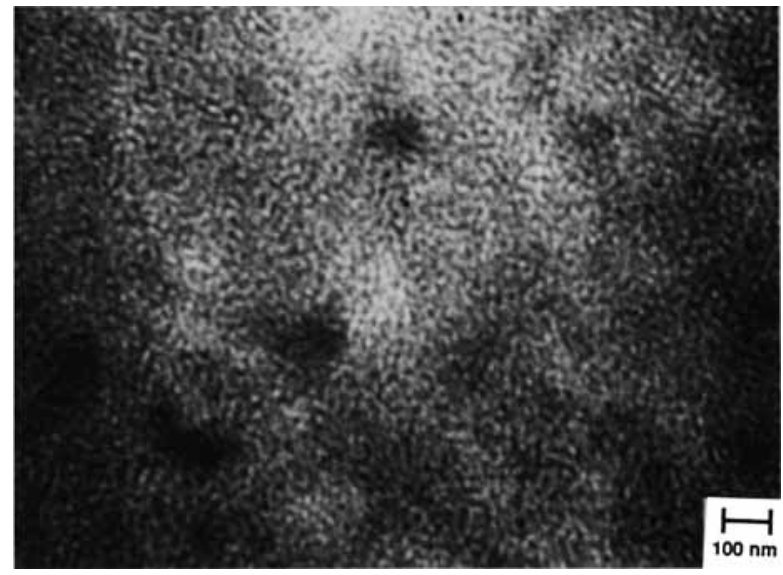

(c)

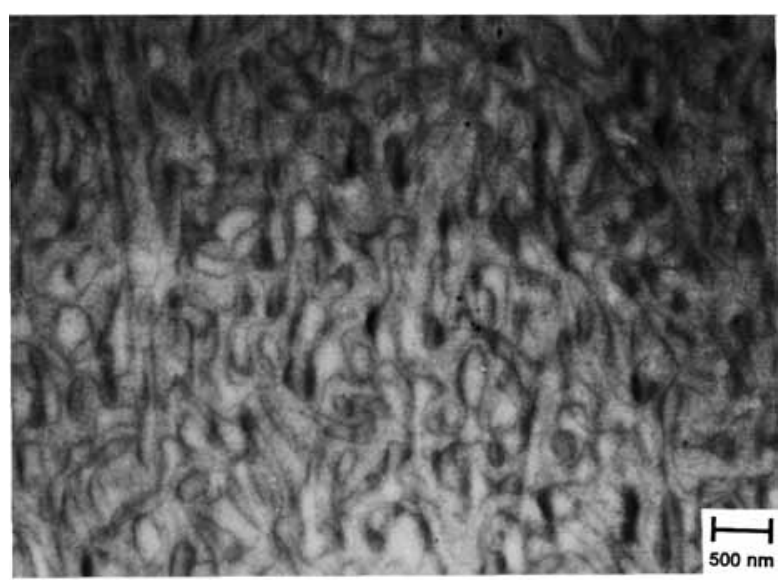

(b)

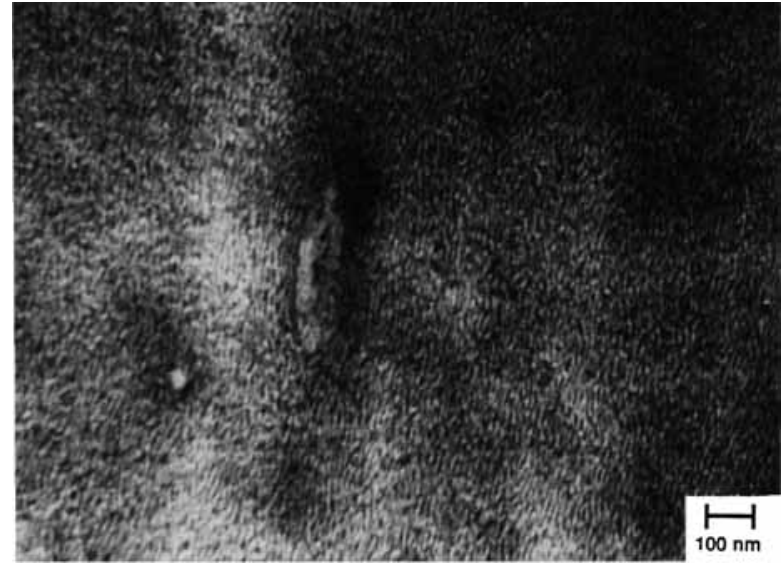

(d)

Figure 7 (a) TEM micrograph of copolymer AB-1; magnification 9000X. (b) TEM micrograph of copolymer AB-3; magnification 21,000×. (c) TEM micrograph of copolymer AB-2; magnification $90,000 \times$. (d) TEM micrograph of copolymer AB-6; magnification $90,000 \times$.

\section{Copolymer Characterization by Permeability and Permselectivity Measurements}

Using a copolymer system made from the prepolymers SI-6 and HSi-2, with varying polysiloxane content in the copolymer-from 25 to $100 \mathrm{wt} \%$, pervaporation measurements were performed. The permeand was water that only slightly swells the hydrophobic copolymer system and therefore hardly changes the copolymer morphology during measurement. The experimental pervaporation results were compared to some copolymer permeability models developed for different copolymer morphologies calculating with permeabilities of pure copolymer compounds. ${ }^{4,5,26-29}$ The aim was to obtain information about changes in copolymer morphology by varying copolymer composition ratios. Of special interest was the change in continuous copolymer phase with rising polysiloxane content.

\section{Models without Copolymer Microphase Inversion $4,5,27,28$}

- Parallel model: Lamellar with parallel orientation of copolymer phases vs. transport direction; permeability calculation ( $P$ : overall permeability of copolymer, $P_{\mathrm{A} / \mathrm{B}}$ permeability of pure polymers $A / B$; polymer $A$ is in our case the glassy, low-permeability poly (styrene-statisoprene); polymer B is the elastomeric, highlypermeable polysiloxane):

$$
P=\varphi_{\mathrm{A}} P_{\mathrm{A}}+\varphi_{\mathrm{B}} P_{\mathrm{B}}
$$


- Serial model: Lamellar with perpendicular orientation of copolymer phases vs. transport direction; the least permeable copolymer component controls the transport properties:

$$
\frac{1}{P}=\frac{\varphi_{\mathrm{A}}}{P_{\mathrm{A}}}+\frac{\varphi_{\mathrm{B}}}{P_{\mathrm{B}}}
$$

- Maxwell: Nearly impermeable spheres of polymer $A$ in permeable polymer matrix $B$; spheres very small and independent from each other:

$$
P=P_{\mathrm{B}} \frac{P_{\mathrm{A}}+2 P_{\mathrm{B}}-2 \varphi_{\mathrm{A}}\left(P_{\mathrm{B}}-P_{\mathrm{A}}\right)}{P_{\mathrm{A}}+2 P_{\mathrm{B}}+\varphi_{\mathrm{A}}\left(P_{\mathrm{B}}-P_{\mathrm{A}}\right)}
$$

- Bruggeman: Elongated, nearly impermeable particles $\mathrm{A}$ in permeable matrix $\mathrm{B} ; P_{\mathrm{A}} \approx 0$ :

$$
P=P_{\mathrm{B}}\left(\varphi_{\mathrm{B}}\right)^{3 / 2}
$$

- Boettcher: Impermeable spheres A in permeable matrix B:

$$
P=P_{\mathrm{B}}\left(1-1,5 \varphi_{\mathrm{A}}\right)
$$

Figure 8 shows the application of the aforementioned models (except Maxwell model) to the copolymer system, compared to the experimental results. The experimental $\mathrm{H}_{2} \mathrm{O}$ pervaporation results lie on the serial model curve at $\varphi_{\text {PDMS }}$ content range from 0 to 0.36 and near the Boettcher model curve at $\varphi_{\text {PDMS }}$ $>0.36$. This can be explained in the following way: In the $\varphi_{\text {PDMS }}$ content range from 0 to 0.36 , the low permeability glassy copolymer component SI- 6 controls the permeability properties-the SI- 6 component builds up the continuous copolymer phase. In the $\varphi_{\text {PDMS }}$ content range $>0.36$, the continuous copolymer phase consists of elastomeric polysiloxane that controls the permeability behavior. The glassy SI-6 copolymer component is dispersed in the shape of spheres within a polysiloxane matrix. From this, it can be derived that a copolymer microphase inversion takes place with a percolation point in the region of $\varphi_{\mathrm{PDMS}} \approx 0.36$. The value of the percolation point is given by the point of intersection between the Boettcher and the serial model curve.

\section{Robeson Mode/ ${ }^{29}$}

The Robeson model takes into account the existence of microphase inversion and, therefore, the existence of a percolation point. The percolation point is the content where the more permeable copolymer component begins to form continuous channels within

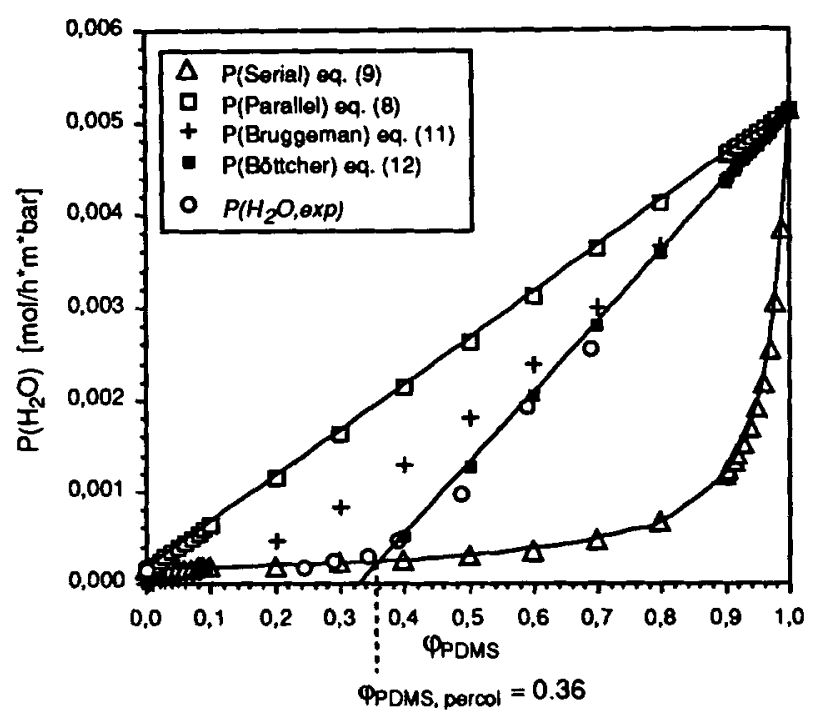

Figure 8 Experimental $\mathrm{H}_{2} \mathrm{O}$ pervaporation results of copolymer system made from SI-6 and HSi-2, compared to special model plots based on the pure $\mathrm{H}_{2} \mathrm{O}$ permeabilities of prepolymers SI-6 and polysiloxane; pervaporation temperature $20^{\circ} \mathrm{C}$. Point of intersection between $P$ (serial) curve $(\Rightarrow$ continuous glassy SI-6 microphase) and $\mathrm{P}$ (Boettcher) curve $(\Rightarrow$ continuous elastomeric $\mathrm{HSi}-2$ microphase, with dispersed SI-6 particles) yields percolation point of $\mathrm{HSi}-2$ microphase in SI-6/HSi-2 copolymer $\left(\varphi_{\text {PDMS,percol. }}=0.36\right)$.

the polymer matrix. Passing the percolation point results in a strong increase of permeability. The model of Robeson combines the Maxwell model with the change in continuous copolymer phase. The equation for the Robeson model is given by

$$
P=X_{\mathrm{A}} P(\mathrm{~A})+X_{\mathrm{B}} P(\mathrm{~B})
$$

with

$$
P(\mathrm{~B})=P_{\mathrm{B}} \frac{P_{\mathrm{A}}+2 P_{\mathrm{B}}-2 \varphi_{\mathrm{A}}\left(P_{\mathrm{B}}-P_{\mathrm{A}}\right)}{P_{\mathrm{A}}+2 P_{\mathrm{B}}+\varphi_{\mathrm{A}}\left(P_{\mathrm{B}}-P_{\mathrm{A}}\right)}
$$

Maxwell equation, phase $\mathrm{B}$ continuous, $P(\mathrm{~B})$ is overall permeability;

$$
P(\mathrm{~A})=P_{\mathrm{A}} \frac{P_{\mathrm{B}}+2 P_{\mathrm{A}}-2 \varphi_{\mathrm{B}}\left(P_{\mathrm{A}}-P_{\mathrm{B}}\right)}{P_{\mathrm{B}}+2 P_{\mathrm{A}}+\varphi_{\mathrm{B}}\left(P_{\mathrm{A}}-P_{\mathrm{B}}\right)}
$$

Maxwell equation, phase A continuous, $P(\mathrm{~A})$ is overall permeability.

$X_{\mathrm{A} / \mathrm{B}}$ is the contribution of phase $\mathrm{A} / \mathrm{B}$ to the entire continuous phase. Therefore, eq. (14) must be valid:

$$
X_{\mathrm{A}}+X_{\mathrm{B}}=1
$$


As an example, the value " $X_{\mathrm{PDMS}}=0.3$ " means that PDMS has a share of $30 \%$ (and the poly (styrenestat-isoprene) a share of $70 \%$ [see eq. (14)] to the entire continuous microphase in the copolymer. The percolation point of the more permeable copolymer component $B$ (here $B=P D M S$ ) is given by the first appearance of $X_{B}$ values $>0$.

In Figure 9, the Robeson model plot for $\mathrm{H}_{2} \mathrm{O}$ pervaporation of the copolymer system SI-6/HSi-2 is shown. Pervaporation experiments were performed at $20^{\circ} \mathrm{C}$.

The percolation point of the polysiloxane phase in the copolymer system is given by the point of intersection between the experimental water permeability curve and the calculated Robeson model curve [eq. (13)] for $X$ (polysiloxane) $=0$ (see Fig. 9 ). The percolation point of the copolymer system is determined to be at a polysiloxane content of $\varphi$ $=0.36$. This value is the same as the percolation point value estimated by the special model plot.

\section{Permselectivity Measurements of the Copolymer System SI-6/HSi-2}

Recently, it was shown by Kim et al. that the estimation of permselectivity behavior provides information about the morphology of copolymers. ${ }^{30} \mathrm{Kim}$ et al. investigated the ethanol/water permselectivity behavior of cationic/anionic IPN membranes and related the ethanol/water permselectivity properties to the IPN morphology.

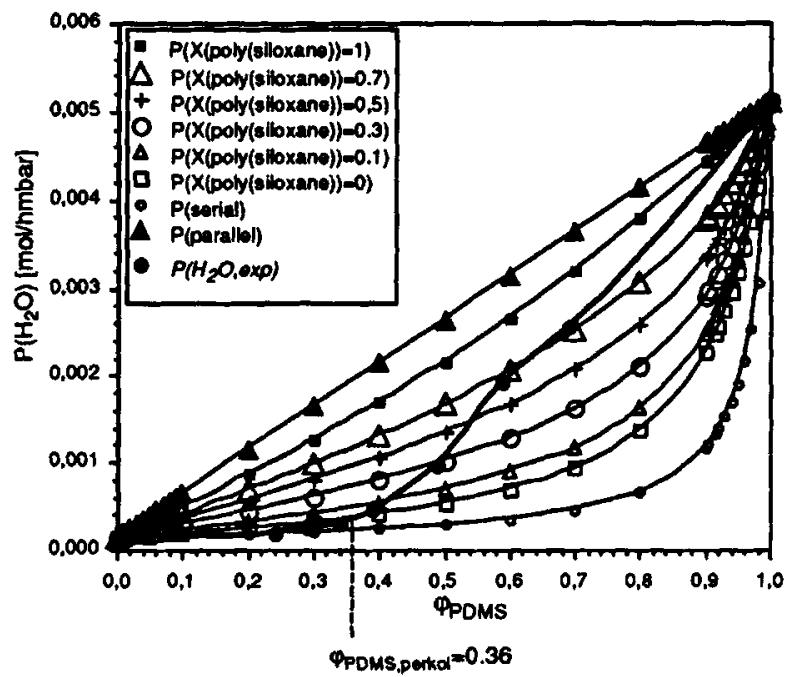

Figure 9 Robeson model plot for $\mathrm{H}_{2} \mathrm{O}$ pervaporation of copolymer system SI-6/HSi-2. Point of intersection between interpolated experimental $P\left(\mathrm{H}_{2} \mathrm{O}\right)$ curve and calculated $P(X$ (polysiloxane $)=0)$ curve yields the percolation point of $\mathrm{HSi}-2$ microphase in SI-6/HSi-2 copolymer $\left(\varphi_{\text {PDMS,percol. }}=0.36\right)$.

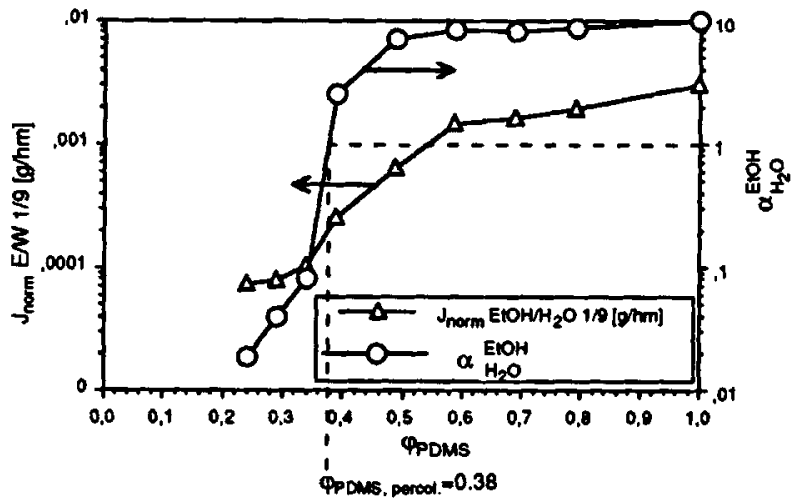

Figure 10 Separation factor $\alpha_{\mathrm{H}_{2} \mathrm{OH}}^{\mathrm{EtOH}}$ and normed flow $J_{\text {norm }}$ for pervaporation of $10 \mathrm{wt} \% \mathrm{EtOH} / 90 \mathrm{wt} \%$ water mixture through membranes of copolymer system SI-6/ HSi-2 in dependence on the polysiloxane mass fraction; pervaporation temp $20^{\circ} \mathrm{C}$. The PDMS volume fraction $\varphi_{\text {PDMS }}$ where $\alpha_{\mathrm{H}_{2} \mathrm{O}}^{\mathrm{EtOH}}$ becomes $>1$ is estimated as the percolation point of the $\mathrm{HSi}-2$ microphase in SI-6/HSi-2 copolymer $\left(\varphi_{\text {PDMS,percol. }}=0.38\right)$.

Because our aim was also to relate the permselectivity behavior to the morphology of our AB-copolymer system, we determined, in addition to $\mathrm{H}_{2} \mathrm{O}$ pervaporation measurements, the ethanol/water separation factors of the copolymer system SI-6/ HSi-2 over a broad range of siloxane content. The aim of our ethanol/water mixture pervaporation experiments was to confirm the prediction of permselectivity behavior stated in the "Basic Considerations" section of this article, i.e., that copolymers with elastomeric polysiloxane continuous phase should enrich ethanol in the pervaporation of ethanol/water mixtures, whereas copolymers with a continuous glassy polymer phase should be waterselective. In Figure 10, the ethanol/water separation factor $\alpha \mathrm{H}_{2} \mathrm{O}$ and "normed" flow $J_{\text {norm }}$ for pervaporation of 10 wt \% ethanol $/ 90 \mathrm{wt} \%$ water mixtures are related to polysiloxane content of the SI-6/HSi2 copolymer system.

From the diagram in Figure 10, it is seen that, in the region of $\varphi_{\text {PDMS }} \approx 0.35-0.45$, the ethanol / water separation factor changes sharply. This results can also be explained as being due to the change in copolymer continuous microphases from glassy SI-6 continuous microphase at $\varphi_{\text {PDMS }} \leq 0.35$ to continuous elastomeric $\mathrm{HSi}-2$ microphase at $\varphi_{\mathrm{PDMS}} \geq 0.45$.

The PDMS volume fraction $\varphi_{\text {PDMS }}$, where $\alpha \underset{\mathrm{H}_{2} \mathrm{O}}{\mathrm{EtOH}}$ becomes $>1$, is estimated as the percolation point of the HSi-2 microphase in the SI-6/HSi-2 copolymer $\left(\varphi_{\mathrm{PDMS} \text {,percol. }}=0.38\right)$, lying very close to the results from the permeability special model and Robeson model analysis. 
Permeability of the Copolymer System SI-6/HSi-2 for a Homologous Alcohol Series

In Figure 11, the permeability coefficients of the pervaporation of a homologous alcohol series are related to their molecular masses for copolymer mem. branes with different polysiloxane contents. Figure 11 shows that permeabilities of copolymers with continuous glassy microphase (copolymers with 30 and $35 \mathrm{wt} \%$ polysiloxane) permeabilities are greatly reduced with increasing molecular mass of the alcohol. The $n$-propanol and $n$-butanol permeabilities for these copolymers are too low to be detected with the pervaporation setup used. For copolymers with a continuous elastomeric phase (shown are 70 and $100 \mathrm{wt} \%$ polysiloxane), permeability rises with increasing molecular mass of the permeand. The permeability behavior of the copolymers with 40 and 50 wt \% polysiloxane is characterized by a permeability decrease from water to methanol, followed by a permeability increase from ethanol on. This observation can be explained by the continuous microphase inversion in this polysiloxane content range: The plasticizing power of water and methanol to the glassy copolymer microphase is not big enough to swell the percolation channels of polysiloxane in the glassy continuous copolymer matrix to such an extent that the overall elastomeric permeability characteristic, increasing the permeability with increasing mol mass of the permeand, is achieved. On the other hand, from ethanol on, the plasticizing power increases so strongly with the alcohol's mol mass that the polysiloxane percolation channels are expanded to be big enough to exhibit the elastomeric overall permeation characteristics of the membrane. In addition, the glassy continuous microphase is plasticized to an increasing extent with increasing mol mass of the alcohol permeands (see below).

\section{Temperature Dependence of the Alcohol Permeability for the SI-6/HSi-2 Copolymer System}

The Arrhenius plots of permeands permeating through polymeric membranes show characteristic kinks in the region of the glass transition temperature of the polymer ${ }^{31}$ because of the strong increase in polymer segment movements on passing the glass

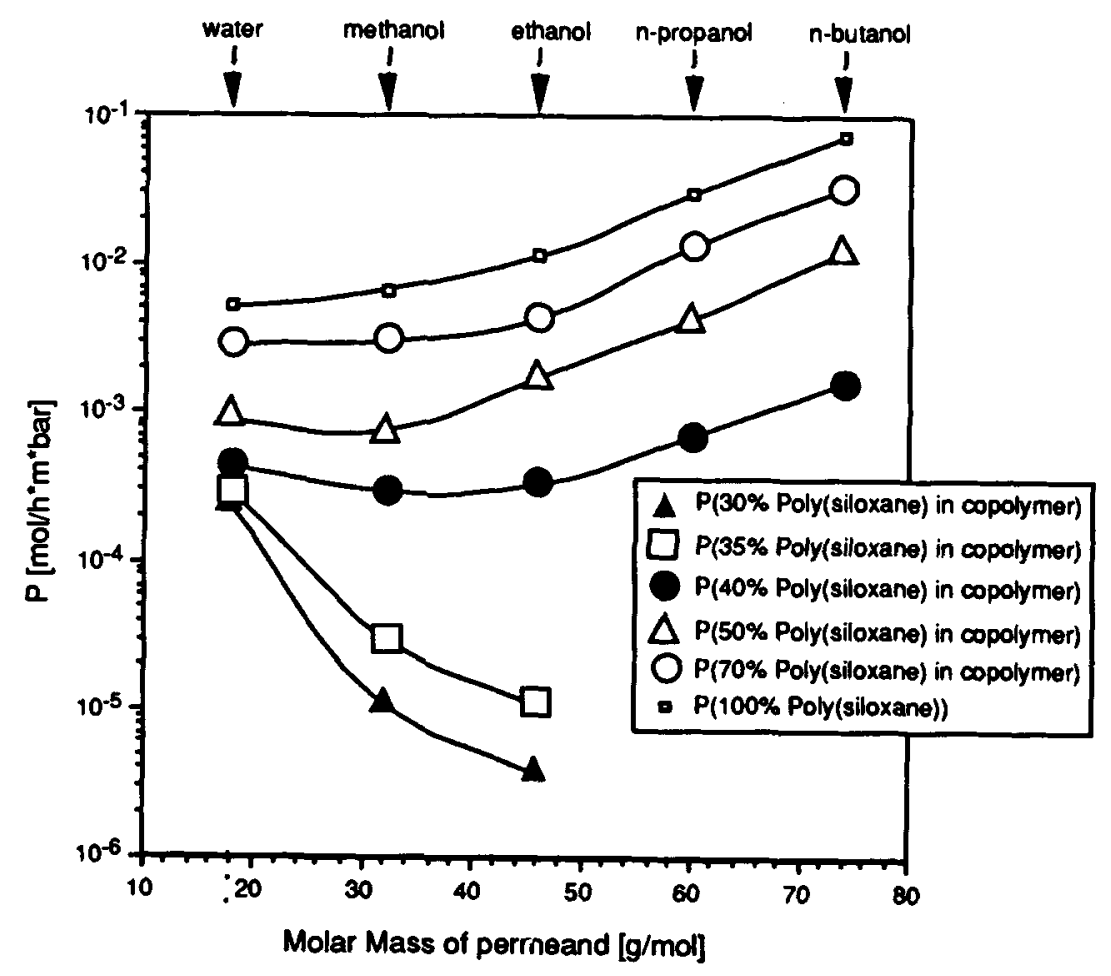

Figure 11 Permeabilities related to mol masses of the permeands for membranes with different polysiloxane contents of a copolymer system made from SI-6 and HSi-2; pervaporation performed at $20^{\circ} \mathrm{C}$. 
transition temperature region. It is possible then to obtain the real glass transition temperature (s) of (co) polymeric membranes in an active, permeating state and, especially, the plasticizing ability of different permeands. In the case of the copolymer system SI-6 $/ \mathrm{HSi}-2\left(T_{g}^{\mathrm{SI}-6}\right.$ in cop., dry $=78^{\circ} \mathrm{C}$, $T_{g}^{\mathrm{HSi}-2 \text { in cop., dry }}=-115.1^{\circ} \mathrm{C}$ ), only the "active" glass transition temperature of the copolymer component SI-6 can be investigated during permeation because all alcohols examined are in the solid state at the glass transition temperature of the $\mathrm{HSi}$ - 2 copolymer component.

Figure 12 shows the $\log$ permeability $/(1 / T)$ curves (Arrhenius plots) of water, ethanol, $n$-propanol, and $n$-butanol through membranes made from $70 \mathrm{wt} \% \mathrm{HSi}-2$ and $30 \mathrm{wt} \% \mathrm{SI}-6$. All permeands cause more or less depressed glass transition temperatures, due to the plasticizing power of the respective permeand. Figure 13 shows that $T_{g}$ depression of the SI-6 copolymer component is dependent

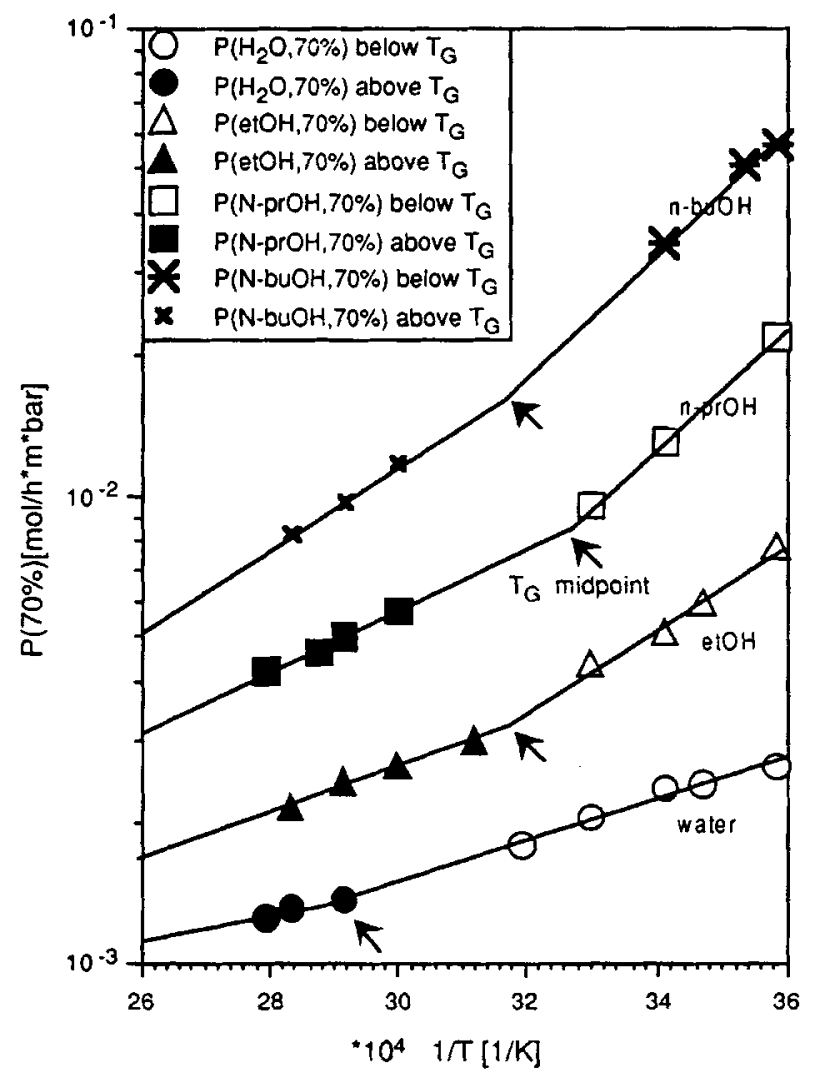

Figure 12 Arrhenius plots for permeability of copolymer membrane made from $30 \mathrm{wt} \% \mathrm{SI}-6$ and $70 \mathrm{wt} \% \mathrm{HSi}$ 2; the arrow shows the kink point of the Arrhenius plot, which denotes the "active" $T_{g}$ of the membrane during permeation.

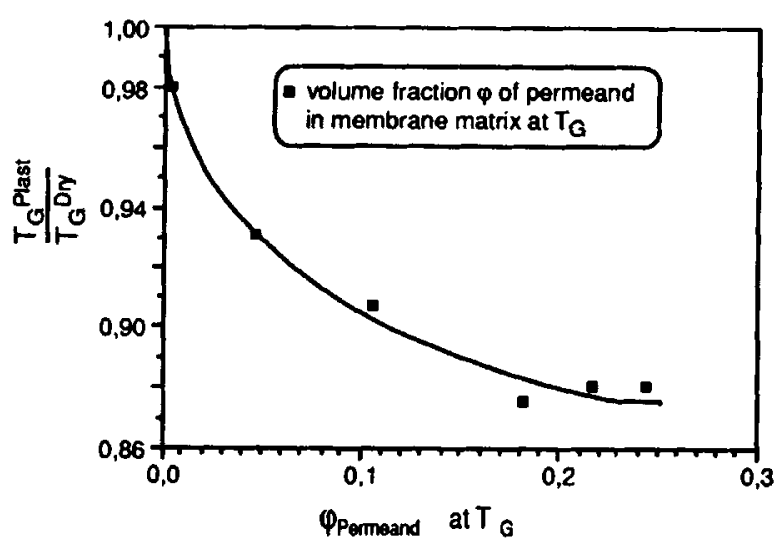

Figure 13 Dependence of $T_{g}$ depression, expressed by the quotient $T_{g}^{\text {plast }} / T_{g}^{\text {Dry }}$ on volume fraction $\varphi$ of permeand in the membrane.

upon concentration of permeand vapor in the membrane matrix.

The higher the volume fraction of the permeand in the membrane, the lower is the "active" $T_{g}$ and, therefore, the plasticizing power of the permeating component. As an example, the water quantity sorbed in the membrane matrix is very little, $\varphi_{\text {water,mem }}=0.0029$, due to the strongly hydrophobic nature of the copolymer system. That leads to a $T_{g}$ depression of only $9.7^{\circ}$ during permeation (from $78^{\circ} \mathrm{C}$ in the dry to $68.3^{\circ} \mathrm{C}$ in the swollen membrane state), whereas $n$-propanol has a $\varphi_{n \text {-proH,mem }}=0.218$, which leads to a $T_{g}$ decrease of $44.3^{\circ}$ during permeation (from $78^{\circ} \mathrm{C}$ in the dry to $33.7^{\circ} \mathrm{C}$ in the swollen membrane state). $n$-Propanol is more hydrophobic than is water.

\section{CONCLUSIONS}

A newly developed copolymer system has been synthesized and characterized. In the synthesis of the copolymer system, many parameters are changeable. In addition, a great number of prepolymers can be used for copolymer synthesis using this technology. Therefore, the copolymers are good model systems for investigation of the influence of different material and reaction parameters to the morphology of the resulting copolymers. The copolymers show a phase-separated morphology, due to incompatibility of the prepolymers. It could be shown that permeability and permselectivity measurements are well suited to augment common characterization methods for determination of copolymer morphology. Copolymer microphase inversion was proven to take 
place in the synthesized copolymer systems and the numerical value of the percolation point was estimated. The prediction for ethanol/water permselectivity was confirmed: In the permeation of ethanol/water mixtures, copolymers with an elastomeric continuous phase enrich ethanol because the permeabilities increase with permeand's molecular mass. On the other hand, copolymers with a glassy continuous phase show water-selectivity because of decreasing permeabilities with permeand's molecular mass.

The synthesized copolymers with an elastomeric continuous phase have potential for the separation of organic solvents from waste gas, waste water, or biosuspensions because of their permeation and permselectivity characteristics and their mechanical, thermal, and chemical stability.

\section{REFERENCES}

1. H. Strathmann, C.-M. Bell, and J. Kerres, Desalination, 77, 259 (1990).

2. Y. Nagase, S. Mori, and K. Matsui, J. Appl. Polym. Sci., 37, 1259 (1989).

3. K. Ishihara and K. Matsui, J. Appl. Polym. Sci., 34, 437 (1987).

4. J. A. Barrie, P. Sagoo, and A. G. Thomas, J. Membr. Sci., 43, 229 (1989).

5. J. A. Barrie and K. Munday, J. Membr. Sci., 13, 175 (1983).

6. C.-M. Bell, F. J. Gerner, and H. Strathmann, J. Membr. Sci., 36, 315 (1988).

7. H. Strathmann, Trennung von molekularen Mischungen mit Hilfe synthetischer Membranen, 1. Aufl., Steinkopff Verlag, Darmstadt, 1979.

8. C.-M. Bell, Dissertation, Universität Stuttgart, 1987.

9. J. Kerres, Dissertation, Universität Stuttgart, 1991.

10. S. P. Chen and J. A. Edin, Polym. Eng. Sci., 20(1), 40 (1980).
11. M. Mulder, Basic Principles of Membrane Technology, Kluver, Dordrecht, 1992, pp. 171-172.

12. H. Horacek, Makromol. Chem. Suppl., 1, 415 (1975).

13. T. Kajijama, Y. Nagata, S. Washizu, and M. Takayanagi, J. Membr. Sci., 11, 39-52 (1982).

14. C. H. Bamford and G. C. Eastmond, Polym. Sci. Technol., 4, 165-192 (1974).

15. J. Kerres, H. Strathmann, and G. Fleischmann, DEOffen 4023960 A1 (1992).

16. X. Guo et al., Macromolecules, 23 (24), 5047 (1990).

17. H. L. Hsieh and W. H. Glaze, Rubber Chem. Technol., 43, 22 (1970).

18. M. Morton and L. J. Fetters, Rubber Chem. Technol., 48, 359 (1975).

19. J. Witte, in Houben-Weyl, Methoden der organischen Chemie, Bd. E 20 Makromolekulare Stoffe, 4.Auflage, H. Bartl and J. Falbe, Eds., Georg Thieme Verlag, Stuttgart, New York, 1987, S.114.

20. W. Hellermann, K.-H. Nordsiek, J. Wolpers, and P. Sunder-Plassmann, DE-Offen 3707434 A 1 (1987).

21. A. Davidjan et al., Makromol. Chem., 177, 2469 (1976)

22. G. Wohlleben, Angew. Chem., 67, 741 (1955).

23. G. Wohlleben et al., Angew. Chem., 64, 103 (1952).

24. T. Itoh, H. Toya, K. Ishihara, and I. Shinohara, J. Appl. Polym. Sci., 30, 179 (1985).

25. W. L. Senn, Anal. Chem. Acta, 29, 505 (1963).

26. A. Ferdinand, Dissertation, TU Berlin, D 83, 1986.

27. J. Crank and G. S. Park, in Diffusion in Polymers, J. Crank and G. S. Park, Eds. Academic Press, London, New York, 1968.

28. A. L. Ievlev and V. V. Teplyakov, in Proceedings of the 8th Summer School in Membrane Science, Sept. 17-21, Gargnano, Italy, 1990.

29. L. M. Robeson, A. Noshay, M. Matzner, and C. M. Merriam, Angew. Makromol. Chem., 29/30, 47 (1973).

30. Y. K. Lee, T.-M. Tak, D. S. Lee, and S. C. Kim, J. Membr. Sci., 52, 157 (1990).

31. N. N. Li and R. B. Long, AICHE J., 15 (1), 73 (1969).

Received September 16, 1992

Accepted December 21, 1992 